\title{
ESTUDIANTES DE ÁRABE DE ORIGEN MARROQUÍ EN LA UNIVERSIDAD AUTÓNOMA DE MADRID: CONCIENCIA E IDENTIDAD LINGÜÍSTICA
}

\author{
Francisco MOSCOSO GARCÍA* \\ Universidad Autónoma de Madrid
}

BIBLID [1133-8571] 26 (2019) 06.1-24.

Resumen: Presentamos los resultados de un cuestionario llevado a cabo en la Facultad de Filosofía y Letras de la Universidad Autónoma de Madrid durante el curso académico 2017-2018. Participaron en él treinta y un estudiantes de origen marroquí, siendo la mayoría del Itinerario de Árabe del Grado en Estudios de Asia y África. Nuestra intención es continuar este estudio y extenderlo a otros estudiantes de árabe del resto de universidades españolas. El cuestionario consta de cuarenta y tres preguntas que han sido divididas en estos apartados: datos personales, aprendizaje, nivel de la lengua nativa, nivel de español y árabe clásico, uso cotidiano de las competencias lingǘsticas y consideraciones personales sobre las lenguas que utilizan.

Palabras clave: Árabe marroquí, Árabe clásico, Amazige, Español, conciencia lingüística.

Abstract: «Arabic students of Moroccan origin at the Universidad Autónoma of Madrid: Linguistic awareness and identity». In this paper, we present the results of a survey, conducted at the Faculty of Letters of the Universidad Autónoma of Madrid, during the academic year 2017-2018. Thirty-one students participated in the survey; all of them are of Moroccan origin and all majoring in Asian and African Studies, Arabic philology. We aim to continue working in this direction and offer this questionnaire to other students with Moroccan background, who study at other Spanish universities. The survey consists of forty-three questions and has the following sections: personal data, learning, native language level, level of Spanish and classical Arabic, daily use of language skills and some personal considerations about the languages that they know.

Key words: Moroccan Arabic, Classical Arabic, Amazigh, Spanish, Linguistic Awareness.

* Profesor titular de Árabe marroquí y Árabe literal, Dpto. de Estudios Árabes e Islámicos y Estudios Orientales. E-mail: francisco.moscoso@uam.es. Código Orcid: 0000-0002-2880-4540. 


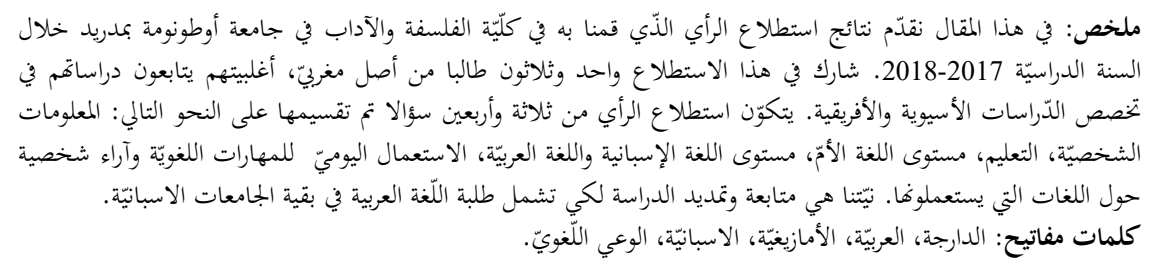

\section{Introducción}

Nuestra intención a partir de este trabajo inicial será desvelar la conciencia lingüística que tienen nuestros estudiantes de lengua árabe en la Facultad de Filosofía y Letras de la Universidad Autónoma de Madrid en relación al árabe marroquí. Al mismo tiempo, se hace necesario observar la conciencia lingüística en relación a la variante hermana dominante, el árabe clásico, y a otra de las lenguas nativas de Marruecos, el amazige.

Para llevar a cabo el estudio, hemos aplicado un cuestionario, entregado en papel, con cuarenta y tres preguntas a treinta y un alumnos durante el curso 2017-2018. Nuestra intención es seguir trabajando en este sentido y aplicarlo a otros alumnos de otras universidades españoles que cursan estudios de árabe y cuyo origen es marroquí. Los cuestionarios fueron entregados sin el nombre del alumno, garantizando así su anonimato. Todas las cuestiones se presentan cerradas, en algún caso se da la opción de elegir dos o más respuestas con un orden de prioridad, y tan solo tres preguntas son para que el alumno diera su opinión personal. No queremos dejar este espacio sin expresar nuestro agradecimiento a nuestros alumnos por su amabilidad al aceptar rellenar y entregarnos el cuestionario. Por último, es importante apuntar que para el análisis de los datos nos hemos servido del editor de datos IBM SPSS Statistics Visor cuyos derechos tiene adquiridos la Universidad Autónoma de Madrid.

En España contamos con estudios que han empleado también un cuestionario; se trata de los llevados a cabo por Valera y Aguilar (2013) a estudiantes españoles de árabe de Murcia y Casa Árabe sobre su percepción en relación a las clases que han recibido; y también de Aguilar y Fernández (2016), cuyo estudio, de las mismas características que el anterior, es ampliado a otras universidades españolas. Fuera de nuestro país, sobresale el análisis realizado por De Ruiter y Ziamari (2014) entre estudiantes universitarios de Marruecos 
los años 2009 a 2012, los cuales cursan sus estudios en árabe clásico o en francés. Estos autores también se valieron del programa SPSS.

El cuestionario está dividido en los apartados que a continuación exponemos, los cuales están relaciones con los datos personales, aprendizaje y nivel de competencias, el uso cotidiano de las competencias lingüísticas y algunas consideraciones personales sobre las lenguas que conoce. Para esta división y para la selección de las preguntas, hemos tomado como modelo lo dicho por De Ruiter y Ziamari (2014: 30-35). Para nuestra presentación, hemos seguido esta clasificación, precedida de una exposición de las lenguas de Marruecos y seguida de las conclusiones.

\section{Lenguas de Marruecos}

Las lenguas oficiales en Marruecos, según el artículo 5, capítulo primero, de la Constitución marroquí en su reforma de 2011, son el árabe y el amazige. Cuando se habla de árabe, se entiende que es la variante clásica, literal, moderna o estándar; y para el amazige, nada se dice de las tres grandes variantes existentes en el país, tarifit, tamazig̀t y tašelhịt. En la Carta Magna, se habla también de la preservación del hassaniyya -variante hablada en la zona Sur, desde el valle del Draa-, y de «la conservación de los dialectos y las identidades culturales» $(a l-D u s t \bar{u} r)^{(1)}$. La conclusión es que las lenguas nativas o maternas no gozan de reconocimiento oficial, tan solo las cultivadas, el árabe clásico y el amazige.

Sin embargo, en los últimos años se ha venido produciendo un debate público entre los partidarios de la normalización y codificación del árabe marroquí y los que siguen apostando únicamente por el árabe clásico (Miller 2012). Los argumentos de unos y otros pueden leerse en Moscoso (2016). De Ruiter y Ziamari (2014: 150) han destacado en sus conclusiones que el árabe clásico es el grand vainqueur du marché linguistique marocain contemporain; siguen diciendo que los estudiantes han manifestado que hablan más en árabe clásico, aunque todavía modestamente y mezclándolo con el árabe marroquí, lo cual quiere decir que ya no es únicamente una lengua de escritura o de lectura. Sería necesario hacer un estudio parecido en las etapas precedentes -primaria, secundaria y bachillerato- para no quedarse únicamente en el sector universitario. Por otro lado, se podría ver el nivel de competencias del árabe

(1) Cf. <https://goo.gl/msBai1> [21 de noviembre de 2018]. 
clásico de todos los estudiantes y el uso de la variante intermedia entre la clásica y el árabe marroquí que se ha convenido en llamar árabe marroquí moderno (Youssi 1992). En este sentido, este autor (Youssi 2013: 30-33) habla del deterioro de las competencias lingüísticas en el Escuela Pública provocado por la enseñanza de una lengua cultivada, el árabe clásico, cuyos principios gramaticales han permanecido inmutables durante catorce siglos. Sigue afirmando este autor que el árabe marroquí moderno es comprendido y practicado por casi un $60 \%$ de los marroquíes -lo cual vendría a corroborar los resultados ofrecidos por De Ruiter y Ziamari anteriormente-, frente a un $40 \%$ que comprende bien el árabe literal y de estos solo un 30\% domina su lectura y un $10 \%$ su escritura. La conclusión para Youssi es la necesidad de normalizar el árabe marroquí moderno.

A pesar de ser una lengua materna cuya escritura no ha sido normalizada y de no gozar de protección por parte de las autoridades, el árabe marroquí se ha venido escribiendo en los últimos años (Elinson 2013). Hay muchos poetas en Marruecos que escriben en esta variante zéjeles, algunos novelistas que se atreven a escribir sus obras enteramente en árabe marroquí, novelistas que escriben en árabe clásico pero que apuestan por combinarlo con el árabe marroquí, o traductores que están volcando obras de la Literatura Universal a la lengua nativa. Todas estas producciones no pueden más que demostrar que el ser humano puede pensar y expresarse en cualquier lengua, y que muchos pueden hacerlo mejor en una lengua nativa que en una cultivada.

En nuestro país, el árabe ceutí, una variante del árabe marroquí perteneciente al área dialectal de la región de Yebala, es la lengua del 42\% de la población española de la ciudad de Ceuta y esta no goza de ningún tipo de reconocimiento en el Estatuto de Autonomía de la ciudad, ni siquiera tiene ningún tipo de protección, estando en situación de peligro debido al monolingüismo militante de los que solo hablan el español, la opresión del poder religioso musulmán que considera como único árabe la variante que tiene sus orígenes en el texto coránico y la falta de conciencia lingüística de los arabófonos, alentada esta última por los dos factores anteriores (Moscoso 2015). Esta situación de minorización se ha visto agravada recientemente, porque el gobierno de Rajoy en 2018 ha excluido el árabe ceutí de su último informe sobre el grado de cumplimiento de la Carta Europea de las Lenguas Minoritarias, alegando que no es una lengua histórica en territorio español -lo cual no es cierto, ya que su presencia en la ciudad data de finales del siglo XIX. 
Por otro lado, el árabe marroquí es una lengua de peso en España, pues constituye una de las dos lenguas -junto al amazige- de la población inmigrante regularizada más importante de nuestro país, con un total de casi 800.000, cifra solo superada por el millón y poco más de $\operatorname{rumanos}^{(2)}$. Este número no tiene en cuenta la población marroquí nacionalizada después de su llegada o a los hijos de la segunda y tercera generación también nacionalizados. No sabemos tampoco la proporción de hablantes de árabe marroquí y de amazige, pero podemos concluir que las dos lenguas tienen una presencia importante en España si tenemos en cuenta el número de originarios procedentes de Marruecos.

\section{Datos personales}

La edad de los alumnos oscila en su gran mayoría entre los 18 y los 23, siendo el porcentaje más alto, con $71 \%$, entre 18 y 21 . En cuanto al género, 25 de ellos son mujeres, y 30 están solteros. De ellos, 11 viven en la ciudad de Madrid y 4 en Rivas Vaciamadrid, el resto vive cada uno en una localidad diferente de la Comunidad de Madrid. 26 de los alumnos viven todavía con sus padres, 2 solos, 1 con su esposa, 1 comparte piso con hispanófonos y 1 comparte piso con hispanófonos y hablantes de árabe marroquí.

Más del 50\%, 17 alumnos, han nacido en Marruecos y 14 en España. Entre estos últimos, 11 han nacido en Madrid y los que lo hicieron en Marruecos, doce fueron en zonas arabófonas y cinco en berberófonas. De los nacidos en aquella zona, 8 lo hicieron en Tánger, Tetuán y Ouazzane, ciudades de la región de Yebala.

(2) Datos del Ministerio de Trabajo, Migraciones y Seguridad Social del Gobierno de España: 〈http://extranjeros.mitramiss.gob.es/es/Estadisticas/operaciones/con-certificado/index.html〉 [02 de diciembre de 2018]. 


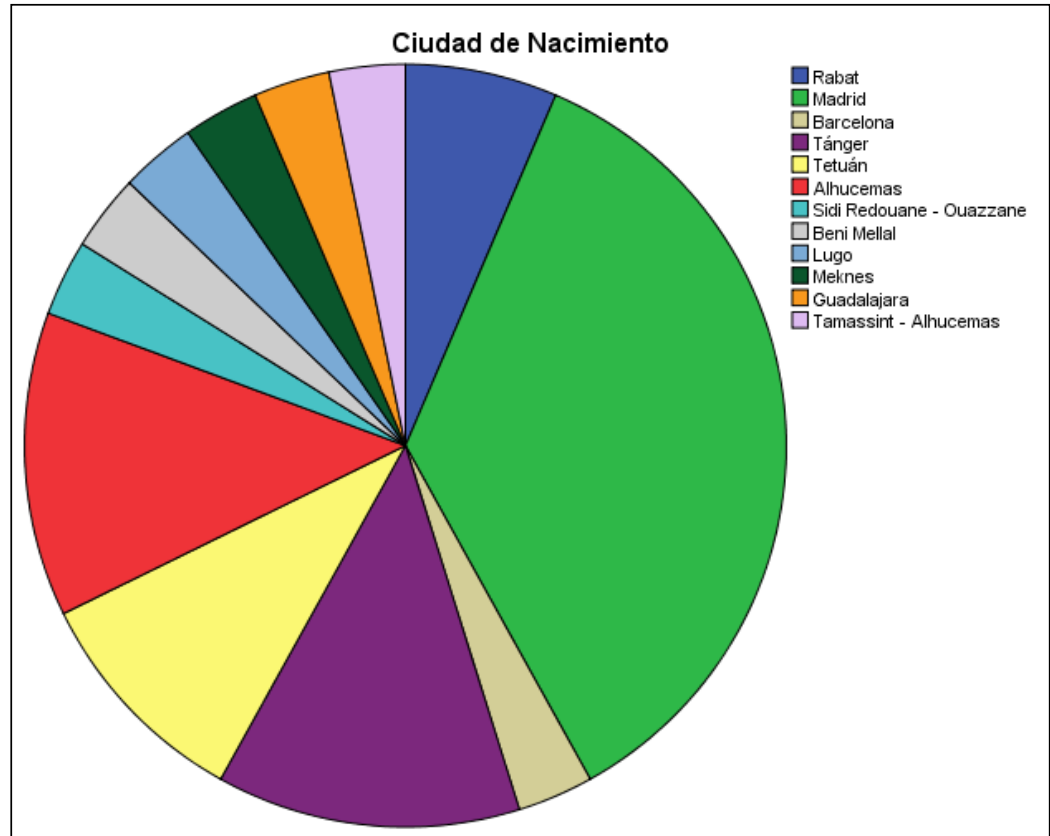

15 de los estudiantes encuestados cursan el Itinerario de árabe en el Grado de Estudios de Asia y África, 14 pertenecen a otros grados de la Facultad de Filosofía y Letras y 2 son de otras facultades. 14 de ellos cursan el primer curso, 9 el segundo, 3 el tercero y 5 el cuarto.

\begin{tabular}{lr|r} 
& Frecuencia & Porcentaje \\
\hline $\begin{array}{l}\text { Estudios de Asia y África } \\
\text { (Itinerario de Árabe) }\end{array}$ & 15 & 48,4 \\
\hline $\begin{array}{l}\text { Lenguas Modernas, Cultura y } \\
\text { Comunicación }\end{array}$ & 3 & 9,7 \\
\hline Estudios Internacionales & 3 & 9,7 \\
\hline Derecho y Ciencias Políticas & 1 & 3,2 \\
\hline
\end{tabular}




\begin{tabular}{lr|r}
\hline Estudios Hispánicos & 4 & 12,9 \\
\hline Química & 1 & 3,2 \\
\hline Estudios ingleses & 3 & 9,7 \\
\hline $\begin{array}{l}\text { Traducción e Interpretación } \\
\text { (francés) }\end{array}$ & 1 & 3,2 \\
\hline Total & 31 & 100,0 \\
\hline
\end{tabular}

\subsection{Lenguas de los padres}

En cuanto al padre, 18 de ellos tienen como lengua nativa el árabe marroquí y 13 el amazige. En el caso de la madre, 20 tienen como lengua nativa la primera y 9 la segunda, siendo solo 1 quien tiene como primera lengua el español y una el árabe marroquí y el francés.

La lengua nativa con la que han crecido los estudiantes ha sido el árabe marroquí para 11 y el amazige para cuatro. 2 han crecido con el español y el resto, un total de 14 lo ha hecho con dos lenguas principalmente, estando entre ellas el árabe marroquí, el español o el amazige.

\begin{tabular}{|c|c|c|}
\hline & Frecuencia & Porcentaje \\
\hline Árabe marroquí & 11 & 35,5 \\
\hline Amazige & 4 & 12,9 \\
\hline Español & 2 & 6,5 \\
\hline $1^{\text {a }}$ Árabe marroquí y $2^{\mathrm{a}}$ Español & 7 & 22,6 \\
\hline $1^{\mathrm{a}}$ Español y $2^{\mathrm{a}}$ Amazige & 1 & 3,2 \\
\hline Árabe marroquí y francés por igual & 1 & 3,2 \\
\hline $1^{\mathrm{a}}$ Amazige - $2^{\mathrm{a}}$ Español & 1 & 3,2 \\
\hline $1^{a}$ Árabe marroquí - $2^{a}$ Amazige & 1 & 3,2 \\
\hline $1^{a}$ Español - $2^{a}$ Árabe marroquí & 1 & 3,2 \\
\hline Árabe marroquí y Español por igual & 1 & 3,2 \\
\hline $\begin{array}{l}1^{a} \text { Amazige - } 2^{a} \text { Español - } 3^{a} \text { Árabe } \\
\text { marroquí }\end{array}$ & 1 & 3,2 \\
\hline Total & 31 & 100,0 \\
\hline
\end{tabular}




\section{Aprendizaje y nivel de competencias}

\subsection{Aprendizaje del español y educación}

14 de los estudiantes dicen que aprendieron el español antes de los tres años y 9 al llegar a la etapa de infantil, entre los tres y los seis años. Son menos los que lo han aprendido con posterioridad: 5 lo hicieron al llegar a la primaria, entre los seis y los doce años, 2 al llegar a la ESO, entre los doce y los dieciséis años, y 1 cuando emigró a España con veintiséis años. De todos ellos, 28 nunca estudiaron el español en Marruecos, tan solo 1 lo hizo en una escuela o instituto español y dos en una escuela o instituto marroquí.

En relación a los estudios previos a la universidad, 22 afirman haber hecho la etapa infantil en España, 8 en Marruecos y 1 no haber cursado esta etapa. La lengua empleada en esta ha sido el español para 21, el español y catalán para 1, el español y el gallego para 1, 6 el árabe clásico, 1 el árabe marroquí y 1 no ha recibido formación. Los estudios de primaria han sido cursados por más alumnos en España, un total de 26, mientras que 4 lo hicieron en Marruecos y 1 entre los dos países. La lengua de enseñanza en esta etapa ha sido el español para 25, el español y el catalán para 1, el español y el gallego para 1, 2 el árabe clásico, 1 en árabe clásico y francés y 1 en español, árabe clásico y francés. La ESO ha sido cursada por 28 alumnos en España y 3 en Marruecos, siendo los mismos resultados para los estudios de bachillerato. La lengua de enseñanza en la ESO ha sido el español para 27 y 1 en gallego y español, el resto lo ha cursado en árabe clásico y francés. La lengua de enseñanza durante el bachillerato ha sido el español para 27 y para 1 el catalán y el español, mientras que 1 lo hizo en español y gallego y 2 en árabe clásico y francés.

Es interesante resaltar aquí la pregunta que se les formuló sobre cuál debería de ser la segunda lengua de estudio de los originarios de Marruecos en la escuela o el instituto. 22 respondieron que el árabe clásico, 3 el árabe marroquí y 1 el amazige. Otros 3 afirman que deberían de ser las tres lenguas anteriores, 1 el árabe clásico y el árabe marroquí y 1 el árabe clásico y el amazige.

\subsection{Nivel de árabe clásico}

Una media de 25 alumnos se mueve en la horquilla Regular - Bien - Muy bien de las cuatro competencias, habla, lectura, escritura y comprensión. Los valores más altos y bajos de esta horquilla son: 12 alumnos dicen que hablan 
«bien» y 3 «muy bien», 9 leen «muy bien» y 8 «regular», 10 escriben «bien»y 6 «regular», y, por último, 10 comprenden «muy bien» y 7 «regular».

\begin{tabular}{|c|c|c|c|}
\hline \multicolumn{2}{|c|}{ Árabe clásico: habla } & Frecuencia & Porcentaje \\
\hline \multirow[t]{6}{*}{ Válido } & Muy bien & 3 & 9,7 \\
\hline & Bien & 12 & 38,7 \\
\hline & Regular & 8 & 25,8 \\
\hline & Un poco & 5 & 16,1 \\
\hline & Nada & 3 & 9,7 \\
\hline & Total & 31 & 100,0 \\
\hline \multicolumn{2}{|c|}{ Árabe clásico: lectura } & Frecuencia & Porcentaje \\
\hline \multirow[t]{6}{*}{$\overline{\text { Válido }}$} & Muy bien & 9 & 29,0 \\
\hline & Bien & 9 & 29,0 \\
\hline & Regular & 8 & 25,8 \\
\hline & Un poco & 3 & 9,7 \\
\hline & Nada & 2 & 6,5 \\
\hline & Total & 31 & 100,0 \\
\hline \multicolumn{2}{|c|}{ Árabe clásico: escritura } & Frecuencia & Porcentaje \\
\hline \multirow[t]{6}{*}{ Válido } & Muy bien & 7 & 22,6 \\
\hline & Bien & 10 & 32,3 \\
\hline & Regular & 6 & 19,4 \\
\hline & Un poco & 4 & 12,9 \\
\hline & Nada & 4 & 12,9 \\
\hline & Total & 31 & 100,0 \\
\hline \multicolumn{2}{|c|}{ Árabe clásico: comprensión } & Frecuencia & Porcentaje \\
\hline \multirow[t]{6}{*}{ Válido } & Muy bien & 10 & 32,3 \\
\hline & Bien & 10 & 32,3 \\
\hline & Regular & 7 & 22,6 \\
\hline & Un poco & 3 & 9,7 \\
\hline & Nada & 1 & 3,2 \\
\hline & Total & 31 & 100,0 \\
\hline
\end{tabular}


Ante la pregunta «¿dónde has estudiado el árabe clásico?», solo responden 29 de los 31. Y de ellos, 18 lo han hecho en España y 10 en Marruecos, y 1 dice no haberlo estudiado. De los que lo han hecho en Marruecos, hay 4 que lo hicieron antes de los seis años, 1 hasta los 9, 1 hasta los 12 años, 1 hasta los 13 años, 2 hasta los 18 años, 1 hasta los 23 años. Si tenemos en cuenta que en la ESO, un alumno puede tener buenas competencias en la lengua en la que estudia, al menos, 5 de nuestros alumnos las tienen.

Antes de los estudios de grado, los alumnos han estudiado árabe clásico en distintos lugares, de los que sobresalen la mezquita: 11 dicen haber estudiado solo en ella, 3 en un centro cultural de la mezquita, 2 en un centro cultural y en la mezquita y 1 en la escuela o el instituto y en la mezquita. Solo 1 dice haberlo estudiado solo en la escuela o el instituto, 3 en la Universidad y 6 en ningún lugar. Por último, habría que apuntar que un estudiante dice haberlo estudiado en un Instituto árabe del centro de Madrid.

En cuanto al estudio del árabe clásico desde la etapa infantil hasta el bachillerato en España, los resultados son los siguientes:

- 2 alumnos dicen haber estudiado dos años durante la etapa infantil y 3 durante los tres años de este ciclo. 26 no lo estudiaron.

- 2 alumnos lo han estudiado durante los seis años de la Primaria, 3 lo han hecho dos años y 1 cinco años. 24 no lo estudiaron y 1 no contesta.

- 1 alumno solo lo cursó durante los cuatro años de la ESO, 1 durante tres años, 1 durante dos y 1 durante uno. 26 estudiante no lo hicieron y 1 no contesta.

- 2 lo hicieron durante los dos años de bachillerato y 1 solo un año. 27 alumnos no estudiaron ningún año y 1 no contesta.

En estos resultados se pone de manifiesto que en los estudios previos a la universidad, la gran mayoría de los alumnos de origen marroquí no recibieron clases de árabe en la escuela o el instituto. Los programas que siguieron para ello son el «Programa de Lengua Árabe y Cultura Marroquí (LCAM)» 4 estudiantes- y el de «Educación Islámica en la Escuela Española»-2 de ellos-.

\subsection{Nivel de árabe marroquí}

La gran mayoría, 21, dice hablar muy bien el árabe marroquí. Este número se divide más o menos en el nivel de lectura: 13 dice leerlo muy bien y 9 bien. En cuanto a la escritura, el nivel baja: 12 lo escribe muy bien, 6 bien y 4 regular. Y en la comprensión, el nivel aumenta: 24 dicen muy bien y 4 bien. 


\begin{tabular}{|c|c|c|c|}
\hline \multicolumn{2}{|c|}{ Nivel AM: habla } & Frecuencia & Porcentaje \\
\hline \multirow[t]{6}{*}{ Válido } & Muy bien & 21 & 67,7 \\
\hline & Bien & 5 & 16,1 \\
\hline & Regular & 3 & 9,7 \\
\hline & Poco & 1 & 3,2 \\
\hline & Nada & 1 & 3,2 \\
\hline & Total & 31 & 100,0 \\
\hline \multicolumn{2}{|c|}{ Nivel AM: lectura } & Frecuencia & Porcentaje \\
\hline \multirow{6}{*}{ Válido } & Muy bien & 13 & 41,9 \\
\hline & Bien & 9 & 29,0 \\
\hline & Regular & 4 & 12,9 \\
\hline & Poco & 2 & 6,5 \\
\hline & Nada & 3 & 9,7 \\
\hline & Total & 31 & 100,0 \\
\hline \multicolumn{2}{|c|}{ Nivel AM: escritura } & Frecuencia & Porcentaje \\
\hline \multirow[t]{6}{*}{$\overline{\text { Válido }}$} & Muy bien & 12 & 38,7 \\
\hline & Bien & 6 & 19,4 \\
\hline & Regular & 4 & 12,9 \\
\hline & Poco & 5 & 16,1 \\
\hline & Nada & 4 & 12,9 \\
\hline & Total & 31 & 100,0 \\
\hline \multicolumn{2}{|c|}{ Nivel AM: comprensión } & Frecuencia & Porcentaje \\
\hline \multirow[t]{5}{*}{$\overline{\text { Válido }}$} & Muy bien & 24 & 77,4 \\
\hline & Bien & 4 & 12,9 \\
\hline & Regular & 1 & 3,2 \\
\hline & Poco & 2 & 6,5 \\
\hline & Total & 31 & 100,0 \\
\hline
\end{tabular}

\subsection{Nivel de amazige}

El amazige tiene una frecuencia de 6 alumnos que lo hablan muy bien y 7 que lo comprenden también muy bien. Para la lectura y la escritura, en los dos solo 1 alumno dice que bien y 2 poco. 20 alumnos dicen no hablar nada de 
amazige y 18 tampoco lo comprenden. En los niveles de lectura y escritura hay 28 alumnos que dicen no tener competencias.

\begin{tabular}{|c|c|c|c|}
\hline \multicolumn{2}{|c|}{ Nivel amazige habla } & Frecuencia & Porcentaje \\
\hline \multirow[t]{6}{*}{ Válido } & Muy bien & 6 & 19,4 \\
\hline & Bien & 1 & 3,2 \\
\hline & Regular & 2 & 6,5 \\
\hline & Poco & 2 & 6,5 \\
\hline & Nada & 20 & 64,5 \\
\hline & Total & 31 & 100,0 \\
\hline \multicolumn{2}{|c|}{ Nivel amazige: lectura } & Frecuencia & Porcentaje \\
\hline \multirow[t]{4}{*}{ Válido } & Bien & 1 & 3,2 \\
\hline & Poco & 2 & 6,5 \\
\hline & $\underline{N a d a}$ & 28 & 90,3 \\
\hline & Total & 31 & 100,0 \\
\hline \multicolumn{2}{|c|}{ Nivel amazige: compr. } & Frecuencia & Porcentaje \\
\hline \multirow[t]{5}{*}{ Válido } & Muy bien & 7 & 22,6 \\
\hline & Bien & 3 & 9,7 \\
\hline & Poco & 3 & 9,7 \\
\hline & $\underline{\text { Nada }}$ & 18 & 58,1 \\
\hline & Total & 31 & 100,0 \\
\hline \multicolumn{2}{|c|}{ Nivel amazige: escritura } & Frecuencia & Porcentaje \\
\hline \multirow[t]{4}{*}{ Válido } & $\underline{B i e n}$ & 1 & 3,2 \\
\hline & Poco & 2 & 6,5 \\
\hline & $\underline{N a d a}$ & 28 & 90,3 \\
\hline & Total & 31 & 100,0 \\
\hline
\end{tabular}

\subsection{Nivel de español}

Las cuatro competencias de español son valoradas por todos en el mismo nivel: 30 hablan, leen, escriben y comprenden muy bien y 1 bien. Esta situación es comprensible si se tiene en cuenta que la mayoría se ha educado en España desde la etapa primaria hasta su llegada a la Universidad. 


\subsection{Lenguas en las que lee y escribe}

3.6.1. 13 alumnos afirman que leen alguna vez libros o textos, en general en papel, en árabe clásico y 12 nunca, 3 dicen que a menudo y 3 mucho. En árabe marroquí, 25 dicen no leer nunca y 4 alguna vez y en amazige 30 dicen no leer nada. Esta información contrasta con los 22 que leen mucho en español o los 8 que lo hacen a menudo.

\begin{tabular}{llr|r} 
Lectura en Árabe clásico & Frecuencia & Porcentaje \\
\hline \multirow{2}{*}{ Válido } & Mucho & 3 & 9,7 \\
\cline { 2 - 4 } & A menudo & 3 & 9,7 \\
\cline { 2 - 4 } & Alguna vez & 13 & 41,9 \\
\cline { 2 - 4 } Nunca & 12 & 38,7 \\
\hline Lectura en Árabe marroquí & Frecuencia & Porcentaje \\
\hline Válido & Mucho & 1 & 31,2 \\
\cline { 2 - 4 } & A menudo & 1 & 3,2 \\
\cline { 2 - 4 } & Alguna vez & 4 & 12,9 \\
\cline { 2 - 4 } & Nunca & 25 & 80,6 \\
\cline { 2 - 4 } & Total & 31 & 100,0 \\
\hline Lectura en español & Frecuencia & Porcentaje \\
\hline Válido & Mucho & 22 & 71,0 \\
\cline { 2 - 4 } & A menudo & 5 & 16,1 \\
\cline { 2 - 4 } & Alguna vez & 4 & 12,9 \\
\cline { 2 - 4 } & Total & 31 & 100,0 \\
\hline Lectura en amazige & Frecuencia & Porcentaje \\
\hline Válido & Mucho & 1 & 3,2 \\
\cline { 2 - 4 } & Nunca & 30 & 96,8 \\
\cline { 2 - 4 } & Total & 31 & 100,0 \\
\hline
\end{tabular}

3.6.2. La lectura en internet varía con respecto a la lectura en papel. En árabe clásico, 13 no lo hacen nunca y 8 alguna vez; el número es más elevado que los 7 que lo hacen a menudo y los 3 mucho. En árabe marroquí, hay 10 que leen a menudo y 2 mucho, sin embargo el número de los que lo hacen nunca, 14, y alguna vez, 5, es más elevado. En amazige, los 31 responden que nunca. El 
porcentaje es mucho más elevado en español, 24 lo hacen mucho y 4 a menudo, solo 3 dicen que alguna vez.

3.6.3. En relación a la escritura, son pocos los que escriben en árabe clásico: solo 1 dice mucho y 5 a menudo, mientras que 17 nunca lo hacen y 8 alguna vez. En árabe marroquí el porcentaje es más elevado: 3 mucho y 7 a menudo, mientras que 15 nunca lo hacen y 6 alguna vez. En amazige, 30 afirman que nunca escriben en esta lengua y 1 alguna vez. La gran mayoría, 25, escriben mucho en español y 5 a menudo, solo 1 dice hacerlo alguna vez.

Se pregunta a los alumnos qué tipo de textos escriben en árabe marroquí. 13 no respondieron a la pregunta y 7 dijeron que ninguno. 3 de ellos afirmaron que escribían mensajes. El resto de alumnos dio distintas respuestas:

- Lo utilizo solo para comunicarme con amigos que viven en Marruecos

- Solo en las redes sociales

- Comentarios, frases cortas

- Cartas a familiares, postales, e-mails, etc.

- Nada más

- Pequeños textos académicos, ya que estoy estudiando árabe en un centro cultural.

Ante la pregunta de si piensan que el árabe marroquí puede escribirse aunque no esté normalizada su escritura, 23 dijeron que sí y 8 que no. Y sobre el tipo de escritura que emplean en las redes sociales, 26 emplean caracteres latino-numéricos, mientras que 2 solo latinos y 2 latino-numéricos y arábigos.

\section{Uso cotidiano de las competencias lingüísticas}

\subsection{Con los padres}

13 alumnos dicen emplear primero el árabe marroquí y en segundo lugar el español con sus padres, mientras que 6 las emplean en el orden contrario. 4 alumnos afirman emplear primero el amazige y en segundo lugar el español. Para los ocho alumnos restantes, hay ocho variantes distintas que pueden verse en el cuadro siguiente: 


\begin{tabular}{|c|c|c|c|}
\hline & & Frecuencia & Porcentaje \\
\hline \multirow[t]{12}{*}{ Válido } & $\begin{array}{l}1^{\mathrm{a}} \text { Español - } 2^{\mathrm{a}} \text { Árabe } \\
\text { marroquí }\end{array}$ & 6 & 19,4 \\
\hline & $\begin{array}{l}1^{a} \text { Árabe marroquí - } 2^{a} \\
\text { Español }\end{array}$ & 13 & 41,9 \\
\hline & $1^{\mathrm{a}}$ Amazige - $2^{\mathrm{a}}$ Español & 4 & 12,9 \\
\hline & $1^{\mathrm{a}}$ Español - $2^{\mathrm{a}}$ Amazige & 1 & 3,2 \\
\hline & $\begin{array}{l}1^{\mathrm{a}} \text { Amazige }-2^{\mathrm{a}} \text { árabe } \\
\text { marroquí }\end{array}$ & 1 & 3,2 \\
\hline & $\begin{array}{l}1^{a} \text { Árabe marroquí - } 2^{a} \\
\text { Amazige }-3^{a} \text { Español }\end{array}$ & 1 & 3,2 \\
\hline & Español con su mujer e hijo & 1 & 3,2 \\
\hline & $\begin{array}{l}1^{\mathrm{a}} \text { Árabe marroquí - } 2^{\mathrm{a}} \\
\text { Amazige y Español por igual }\end{array}$ & 1 & 3,2 \\
\hline & Árabe marroquí & 1 & 3,2 \\
\hline & Amazige & 1 & 3,2 \\
\hline & $\begin{array}{l}1^{\circ} \text { Español - } 2^{\circ} \text { Árabe } \\
\text { marroquí - } 3^{\circ} \text { Árabe clásico }\end{array}$ & 1 & 3,2 \\
\hline & Total & 31 & 100,0 \\
\hline
\end{tabular}

\subsection{Con los hermanos}

Con los hermanos, la situación es al contrario. 15 dicen emplear primero el español y en segundo lugar el árabe marroquí, al igual que 6 emplean el amazige en primer lugar y el español en segundo. Y 5 afirman emplear primero el árabe marroquí y en segundo lugar el español. Tan solo 3 emplean siempre el español.

\begin{tabular}{|c|c|c|c|}
\hline & & Frecuencia & Porcentaje \\
\hline \multirow[t]{4}{*}{ Válido } & $\begin{array}{l}1^{\mathrm{a}} \text { Español - } 2^{\mathrm{a}} \text { Árabe } \\
\text { marroquí }\end{array}$ & 15 & 48,4 \\
\hline & $\begin{array}{l}1^{a} \text { Árabe marroquí - } 2^{a} \\
\text { Español }\end{array}$ & 5 & 16,1 \\
\hline & $1^{\mathrm{a}}$ Español - $2^{\mathrm{a}}$ Amazige & 6 & 19,4 \\
\hline & Español & 3 & 9,7 \\
\hline
\end{tabular}




\begin{tabular}{lr|r}
$\begin{array}{l}\text { Árabe marroquí y Español por } \\
\text { igual }\end{array}$ & 1 & 3,2 \\
$\begin{array}{l}1^{\circ} \text { Español - 2 } \\
\text { marrórabuí - 30 Árabe clásico }\end{array}$ & 1 & 3,2 \\
\hline \begin{tabular}{l} 
Total \\
\hline
\end{tabular} & 31 & 100,0 \\
\hline
\end{tabular}

\subsection{Con los amigos}

Con los amigos, el uso del español como primera lengua, seguida del árabe marroquí, tiene una frecuencia de 17, mientras que el contrario solo 4. Hay 2 que dicen que emplean estas dos lengua simultáneamente y 5 que solo emplean el español.

\begin{tabular}{|c|c|c|c|}
\hline & & Frecuencia & Porcentaje \\
\hline \multirow[t]{8}{*}{$\overline{\text { Válido }}$} & $\begin{array}{l}1^{\mathrm{a}} \text { Español - } 2^{\mathrm{a}} \text { Árabe } \\
\text { marroquí }\end{array}$ & 17 & 54,8 \\
\hline & $\begin{array}{l}1^{a} \text { Árabe marroquí - } 2^{a} \\
\text { Español }\end{array}$ & 4 & 12,9 \\
\hline & $\begin{array}{l}\text { Árabe marroquí y Español al } \\
\text { mismo nivel }\end{array}$ & 2 & 6,5 \\
\hline & Español & 5 & 16,1 \\
\hline & $\begin{array}{l}1^{\mathrm{a}} \text { Español - } 2^{\mathrm{a}} \text { Árabe } \\
\text { marroquí }-3^{\mathrm{a}} \text { Amazige }\end{array}$ & 1 & 3,2 \\
\hline & $\begin{array}{l}\text { Árabe marroquí y Español por } \\
\text { igual }\end{array}$ & 1 & 3,2 \\
\hline & $\begin{array}{l}1^{\circ} \text { Español - } 2^{\circ} \text { Árabe } \\
\text { marroquí - } 3^{\circ} \text { Árabe clásico }\end{array}$ & 1 & 3,2 \\
\hline & Total & 31 & 100,0 \\
\hline
\end{tabular}

\section{Consideraciones lingüísticas}

Ante la pregunta de cuál es la lengua materna o nativa de los árabes, 12 dicen que es el árabe clásico y 14 las variantes árabes de cada país y 4 dicen que es el dariya. Por consiguiente, son más, 18 , los que son conscientes de que la lengua materna o nativa es la adquirida en la casa al nacer. 


\section{1. Árabe clásico}

Esta variante es considerada como muy bonita por 26 alumnos y 5 como bonita.

\section{2. Árabe marroquí}

Para el árabe marroquí hay más opiniones. Solo 8 dicen que es muy bonito, aunque 14 lo consideran bonito, frente a 6 que dicen que es normal y 3 feo.

\begin{tabular}{llr|r} 
& & Frecuencia & Porcentaje \\
\hline Válido & Muy bonito & 8 & 25,8 \\
\cline { 2 - 4 } & Bonito & 14 & 45,2 \\
\cline { 2 - 4 } & Normal & 6 & 19,4 \\
\cline { 2 - 4 } & Feo & 3 & 9,7 \\
\cline { 2 - 4 } & Total & 31 & 100,0 \\
\hline
\end{tabular}

Otra cuestión es si consideran al árabe marroquí una lengua o un dialecto. 18 de ellos contestaron que es un dialecto y 13 una lengua. El porcentaje de aquel es de un $58,1 \%$. Ante la pregunta de si esta lengua tiene gramática, 23 dijeron que sí, 6 que no y 2 que no lo sabían.

\subsection{Amazige}

La consideración que merece esta lengua sigue siendo positiva, pero en menos grado que las dos anteriores. 8 dicen que es muy bonita, 7 bonita y 7 normal. Sin embargo hay 7 que afirman que es fea y 1 muy fea.

\begin{tabular}{llr|r} 
& Frecuencia & \multicolumn{1}{r}{ Porcentaje } \\
\hline Válido & Muy bonito & 8 & 25,8 \\
\cline { 2 - 4 } & Bonito & 7 & 22,6 \\
\cline { 2 - 4 } Normal & 7 & 22,6 \\
\cline { 2 - 4 } & Feo & 7 & 22,6 \\
\cline { 2 - 4 } Muy feo & 1 & 3,2 \\
\cline { 2 - 4 } No sabe - no contesta & 1 & 3,2 \\
\cline { 2 - 4 } Total & 31 & 100,0 \\
\hline
\end{tabular}




\subsection{Uso de la lengua en la escuela marroquí}

18 de los alumnos piensan que el árabe marroquí se debería de emplear tanto a nivel oral como escrito en la escuela marroquí y 13 piensan lo contrario. $\mathrm{Y}$ ante la pregunta de si solo debería de usarse a nivel oral y no escrito, 10 dicen que sí y 20 que no y 1 no contesta. Y al preguntarles la razón de sus respuestas, estos fueron los comentarios:

¿Crees que en Marruecos se debería emplear el árabe marroquí tanto a nivel oral como escrito? ¿O solo a nivel oral? ¿Por qué? Escribe la razón.

1 Sí. No. Es un dialecto que debe ser enseñado en la Escuela para así poder hablarlo y escribirlo correctamente.

2 Sí. No. Porque los estudiantes tendrán menores problemas de expresarse y desempeñarse académicamente ya que la lengua marroquí es la que emplean a diario y la tienen más dominada. Se podrán expandir más mentalmente.

3 Sí. No. (No da razones)

4. Sí. No. Porque es el idioma más utilizado, con diferencia, y debería tener más importancia

5 Sí. (No contesta). Para que se refleje la lengua oral en la escrita

6 No. Sí. Porque a raíz del árabe clásico pueden escribir y leer en árabe marroquí

7 No. Sí. Porque es más sencillo y común

8 Sí. No. Porque es el más extendido

9 Sí. No. Así pueden aprender también su escritura

10 No. No. El árabe marroquí solo sirve para Marruecos, quitando el Rif. No es muy productivo

11 No. Sí. Para no perder destrezas en el árabe clásico

12 Sí. No. Tanto la oralidad como la escritura deberían ser obligatorias para mejorar el aprendizaje de su lengua y poder aprender otras lenguas nuevas

13 Sí. No. Porque el árabe clásico tiene palabras que pueden tener varios significados y es posible que los niños nunca hayan visto las palabras con las que está escrito el texto

14. Sí. No. Porque es el dialecto que se usa en todos los ámbitos dentro del país

15 Sí. No. Porque es la lengua del país y todos deberían saber manejarla por escrito y hablado 
16 Sí. No. Es una lengua que permite comunicar como cualquiera y es la lengua de juegos en el patio

17 Sí. No. Porque es la lengua que se emplea por el $60 \%$ de los hablantes

18 Sí. No. Por la misma razón antes mencionada

19 No. No. Por el mismo motivo anteriormente citado

20 No. Sí. Porque el árabe marroquí es un dialecto, no una lengua

21 Sí. No. Es importante también la lengua materna

22 No. Sí, Porque a nivel escrito el Ârabe marroquí no tiene una gramática regulada

23 Sí. No. Para poder aprender más rápido y asimilar las letras y palabras

25. Si se decide a aprender una lengua debe ser en todos sus ámbitos para poder controlarla mejor

26 Para que los niños entiendan mejor el árabe

27 Porque es el que la mayoría de los marroquíes hablan

28 Porque se utiliza más el árabe marroquí de forma oral que escrita

29 Parece innecesario

30 Porque solo lo vas a utilizar en Marruecos

31 Realmente es un idioma que nunca se le ha dado mucha importancia en la escritura, porque se ha sustituido por el árabe (clásico). Para mí, debería de escribirse sí, pero eso conllevaría a un buen cambio y volver a comenzar la escritura.

\subsection{Lengua de enseñanza a los hijos}

Ante la pregunta de en qué lengua se hablará a los hijos, las respuestas son bastante heterogéneas, pero todas señalan más de dos lenguas, destacando 11 de ellos que optarán por enseñar el árabe marroquí y el español.

\begin{tabular}{llr|r} 
& Frecuencia & Porcentaje \\
\hline Válido & Árabe marroquí y Español & 11 & 35,5 \\
\cline { 2 - 4 } & Amazige (bereber) y Español & 2 & 6,5 \\
\cline { 2 - 4 } & Español & 2 & 6,5 \\
\hline Árabe marroquí, Español e & 3 & 9,7 \\
Inglés & & \\
\hline Amazige & 1 & 3,2 \\
\cline { 2 - 4 } & Amazige, Español e Inglés & 1 & 3,2 \\
\hline
\end{tabular}




\begin{tabular}{llr|r|}
\hline & $\begin{array}{l}\text { Árabe marroquí, Español y } \\
\text { Francés }\end{array}$ & 2 & 6,5 \\
\hline $\begin{array}{l}\text { Ámazige, Árabe marroquí, } \\
\text { Árabe clásico, Español }\end{array}$ & 1 & 3,2 \\
\hline $\begin{array}{l}\text { Árabe marroquí, Amazige y } \\
\text { Español }\end{array}$ & 2 & 6,5 \\
& $\begin{array}{l}\text { Árabe marroquí, Español y } \\
\text { Gallego }\end{array}$ & 1 & 3,2 \\
& $\begin{array}{l}\text { Árabe marroquí, Árabe } \\
\text { clásico y Español }\end{array}$ & 1 & 9,7 \\
\hline Amazige, Árabe marroquí, & & 3,2 \\
\hline Español, Árabe clásico & 30 & 96,8 \\
\hline Total & Sistema & 1 & 3,2 \\
\hline Perdidos & & & 100,0 \\
\hline
\end{tabular}

5.7. ¿Qué lengua deberían de estudiar en la Escuela y el Instituto en España los originarios de Marruecos? ¿Por qué? Escribe una razón.

Finalmente ofrecemos las opiniones siguientes que dieron prioridad al árabe clásico, un total de 22 , ya que es una lengua con la que se pueden comunicar los árabes, es empleada en los medios de comunicación, tiene perspectivas laborales y es la lengua del Corán. 1 persona dijo que el árabe clásico y el amazige, 1 el árabe marroquí, 3 el árabe marroquí y el árabe clásico y 1 el árabe clásico, el árabe marroquí y el amazige, 1 árabe marroquí y el amazige y 2 no contestan.

1 El árabe clásico y el amazige. Porque el árabe clásico es comprendido por casi todos los países árabes.

2 El árabe clásico. Porque ya sabrán de antemano el dariya o amazige respectivamente quien tenga una $\mathrm{u}$ otra como lengua materna y el árabe clásico les podrá abrir más puertas en el mundo laboral y académico; además de que así no se obliga a uno y a otro a estudiar una lengua que no la tiene como lengua materna.

$3 \mathrm{El}$ árabe clásico. Porque aprendiendo árabe clásico se pueden comunicar con otros países. 
4. El árabe clásico. Porque considero que abre las puertas a comunicarse con personas de todos los países árabes, y no solamente de Marruecos.

5. (no contesta)

6. El árabe clásico. Porque es el más empleado en la lectura y escritura, en la televisión, etc.

7 El árabe clásico. Porque es el idioma (lengua) del Corán

$8 \mathrm{El}$ árabe clásico. Porque es el reconocido

$9 \mathrm{El}$ árabe clásico. Es el que «engloba» todo.

10 El árabe clásico. Porque es el usado en el islam y sirve para comunicarte con cualquier persona del mundo árabe

11. El árabe clásico. Es importante de cara al mundo laboral.

12 El árabe marroquí. Es su lengua nativa y deben aprender a usarla en la escuela.

13 El árabe marroquí. Porque es lo que más han escuchado de sus padres y es lo que han oído, y el árabe clásico como segundo idioma porque la mayoría de los libros están escritos con el árabe clásico

14 Creo que ambas sirven por igual fuera de Marruecos.

15 La dariya podrán tener acceso a ella por medio de la familia, pero al árabe clásico no y desde mi punto de vista es una lengua importante.

$16 \mathrm{El}$ árabe marroquí si es de padres que hablan (dariya) y amazige para los amazigófonos.

17 El árabe clásico. Porque es la lengua que se emplea por el $60 \%$ de los hablantes.

18 El árabe clásico. Porque así podrá salir del ámbito familiar y ser usado en otros lugares, como en las noticias (nacionales)

19 El árabe clásico. Porque permite el acceso a una amplia extensión de libros además de que permite el entendimiento con personas de otros países

20 El árabe clásico, el árabe marroquí y el amazige. Porque considero que las tres lenguas son necesarias para los originarios de Marruecos.

21 El árabe clásico y el árabe marroquí. Para aprender el máximo de lenguas posibles y desarrollar competencias en sus lenguas maternas.

22 El árabe clásico. Porque estudiar el árabe marroquí o el amazige en España sería absurdo cuando en Marruecos no se estudia.

23 El árabe clásico. Es más general, universal.

24. No contesta.

25 El árabe clásico. Porque es la lengua del Corán, nuestro libro sagrado. 
26 El árabe clásico. Es el paraguas de todas las lenguas árabes.

$27 \mathrm{El}$ árabe clásico. Porque te abre más puertas.

$28 \mathrm{El}$ árabe clásico. Porque es la base del árabe marroquí (dariya).

29 El árabe clásico. Está más globalizado

30 El árabe clásico. Para que no se pierda.

31 Porque a través del árabe (clásico) podemos abrir nuestra mente, perfeccionar nuestra lengua, con lo que será más fácil adquirir después los demás idiomas. El árabe se le puede dar más uso y está más evolucionado.

\section{Conclusiones}

El $71 \%$ de los alumnos tiene entre 18 y 21 años, el 80,6\% son mujeres y el $96,8 \%$ son solteros. Todos viven en la Comunidad de Madrid y el 83,9\% vive con sus padres. El 54,8\% ha nacido en Marruecos, y de este porcentaje, 17 alumnos lo han hecho en zonas arabófonas, principalmente la región de Yebala, de donde son 12; y 5 en berberófonas. 15 de ellos están cursando el Itinerario de Árabe del Grado en Estudios de Asia y África y 14 otros grados de la Facultad, los cuales han optado por el Árabe clásico como segunda lengua. En cuanto a la lengua materna del padre, 18 dice que es el árabe marroquí y 13 el amazige, y la de la madre, 20 el árabe marroquí y 9 el amazige.

Podemos decir que las competencias en español fueron adquiridas por la mayoría en la escuela y el instituto en España. De hecho, todos dicen tener un nivel alto de competencias en español. Pocos hicieron la etapa infantil en Marruecos, 8 alumnos. El número baja a 4 en la primaria y a 3 en la secundaria y el bachillerato. Es interesante destacar que 22 de entre ellos piensan que la segunda lengua de enseñanza en la escuela y el instituto en España tiene que ser el árabe clásico, 3 el árabe marroquí y 1 el amazige. Esta opinión pone de manifiesto desde el principio la alta consideración que tienen del árabe clásico.

Esta consideración contrasta con el nivel que dicen tener en cada una de las competencias. Los que comprenden muy bien o bien el árabe clásico son el $64 \%$, en igual número; y los que lo hablan muy bien son 3 frente a 12 bien, es decir, el $48,4 \% .58 \%$ lo leen muy bien o bien, en igual número y 54,9 lo escribe muy bien o bien, 7 en la primera categoría y 10 en la segunda. 18 alumnos dicen haber estudiado esta variante en España y 10 en Marruecos. Los lugares más destacados fuera de la Escuela o el Instituto en España han sido la mezquita, 11 alumnos, y un centro cultural, 5 de ellos. Esta situación contrasta con los que no estudiaron árabe clásico en la Escuela Pública, entre 24 y 27 en las cuatro etapas 
previas a la Universidad. Los que sí lo hicieron, siguieron el programa LCAM, un total de 4, y el de Educación Islámica, 2.

En cuanto a las lenguas maternas, el $67,7 \%$ la habla muy bien y un $77,4 \%$ la comprende muy bien, frente a un $41,9 \%$ que la lee muy bien y un $38,7 \%$ que la escribe muy bien. Esta situación contrasta con el amazige, ya que nadie lee o escribe muy bien en esta lengua. Es indudable que al tratarse de lenguas orales y no normalizadas, estas son empleadas sobre todo en internet o las redes sociales, teniendo mayor presencia y prestigio el árabe marroquí que el amazige.

La lectura de un libro es mucho más empleada en español. El $71 \%$ lo hace mucho en español frente al 9,7\% en árabe clásico y solo un 3,2\% en árabe marroquí y nada en amazige. Y en cuanto a la escritura en papel, los datos en árabe clásico son más bajos, siendo más elevado el porcentaje en árabe marroquí. Un $74 \%$ de los alumnos respondieron que se suele escribir en árabe marroquí aunque no esté normalizada la lengua.

El porcentaje de alumnos que emplea el español primero con sus padres y en segundo lugar el árabe marroquí es de 41,9\%; sin embargo, con los hermanos es al contrario, llegando al 48,4\%, siendo aún mayor con los amigos, un 54,8\%.

Resulta curioso destacar que un $45,2 \%$ piensa que la lengua materna de los árabes es el árabe marroquí, el árabe argelino, el árabe libanés, etc., frente a un $12,9 \%$ que cree que es el dariya y un 38,7\% el árabe clásico. Todos dicen que el árabe clásico es muy bonito o bonito, pero las opiniones están más divididas para el árabe marroquí, siendo la más alta la de «bonito» con un 45,2\%. El $58,1 \%$ contestó que el árabe marroquí es un dialecto y el resto una lengua, pero el 74,2\% afirmó que tiene gramática. La consideración del amazige está más dividida, oscila entre el $25,8 \%$ que lo considera muy bonito y 3,2 muy feo o el 22,6 feo. El 58,1\% de los estudiantes considera que el árabe marroquí debe de ser empleado tanto a nivel oral como escrito en la escuela. Esta información contrasta con la opinión de la lengua que se debería estudiar en la escuela y el instituto en España por parte de los originarios de Marruecos, ya que 22 de los 31 alumnos dijeron que el árabe clásico.

En general, el alumno originario de Marruecos de nuestra facultad tiene unas competencias de español como el resto de españoles, ya que han seguido la mayoría de sus estudios de primaria, secundaria y bachillerato en nuestro país. Tienen una alta consideración del árabe clásico y es la lengua que proponen se enseñe, a pesar de que emplean más el español y el árabe marroquí. Por otro 
lado, consideran que el árabe marroquí es bonito, un dialecto, tiene gramática y debe de ser empleado a nivel oral y escrito en la escuela marroquí.

\section{BIBLIOGRAFÍA}

AGUILAR, Victoria \& FERNÁNDEZ Fonfría, Lidia. 2016. «La conciencia lingüística de los estudiantes de árabe en España». En: Identidad y conciencia lingüística. Actas del VI congreso internacional de árabe marroquí. Francisco Moscoso García \& Adil Moustaoui Sghir (eds.). Madrid, Universidad Autónoma de Madrid. pp. 75-116.

DE RUITER, Jan Jaap \& ZIAMARI, Karima. 2014. Le marché sociolinguistique contemporain du Maroc. Paris, L'Harmattan.

ELINSON, Alexander E. 2013. «Dārija and changing writing practices in Morocco». International Journal of Middle East Studies 45, pp. 715-730.

MOSCOSO GARCÍA, Francisco. 2015. «El árabe ceutí, una lengua minorizada de España». Revista de Estudios de Asia y África 50, 2, pp. 395-493.

MOSCOSO GARCÍA, Francisco. 2016. «Argumentos en defensa del árabe literal en Marruecos». En: Francisco Moscoso García \& Adil Moustaoui Sghir (eds.). Identidad y conciencia lingüística. VI congreso de árabe marroquí. En: Colección Actas CD 14. Madrid, Universidad Autónoma de Madrid, pp. 165-191.

VALERA LABORDA, Abraham \& AGUILAR, Victoria. 2013. «¿Cómo enseñamos árabe? La voz de los alumnos». Revista de Estudios Internacionales Mediterráneos 15, pp. 179-204.

<https://revistas.uam.es/index.php/reim/article/view/926> [06 de octubre de 2018].

YOUSSI, Abderrahim. 1992. Grammaire et lexique de l'arabe marocain moderne. Casablanca, Wallada. 